\title{
Optimization of Castor Oil Transesterification using Central Composite Design (CCD); Chemical Composition of Fatty acids content using Gas Chromatography
}

\author{
P.A.Satyanarayana1, V.Sridevi ${ }^{2 *}$, Chaman Mehtha ${ }^{3}$, B.Venu Gopal ${ }^{4}$ \\ 1,2,4 Department of Chemical Engineering, AU College of Engineering, Andhra University, Visakhapatnam, \\ Andhra Pradesh, India. \\ 3Indian Institute of Science Education and Research, (An Autonomous Institution, Ministry of H.R.D) \\ Mangalam B.O, Karkambadi Road, Tirupati-517501.
}

ABSTRACT: In the present study, the synthesis of fatty acid esters from castor oil using an alkaline catalyst was optimized. The variables were studied using a central composite design. The effects and significance of the models on the response variable and on biodiesel (methyl ester) yield derived from pure castor oil were evaluated using a response surface curve and analysis of variance. The statistical models developed from castor oil methyl ester (COME) for predicting yield showed a good agreement between the experimental and calculated response. A yield of $90.50 \mathrm{wt} \%$ methyl ester was achieved at $1.5 \mathrm{wt} \% \mathrm{KOH}, 60^{\circ} \mathrm{C}$, 7:1 methanol:oil ratio and 90 min reaction time. The composition of the fatty acid methyl ester was determined by Gas Chromatography (GC). Finally, it was concluded that castor oil is distinguished by its high content of ricinoleic acid (about 89.15\%), castor oil unsaturated bond, molecular weight (298), low melting point $\left(5^{\circ} \mathrm{C}\right)$, hence it gained a lot of importance in industrial applications.

KEYWORDS: Transesterification, Castor Oil, methyl ester, CCD, GC.

https://doi.org/10.29294/IJASE.5.4.2019.1106-1117

(C) 2019 Mahendrapublications.com, All rights reserved

\section{INTRODUCTION}

The rising cost and depletion of reserves of mineral oils are becoming the serious threat to the humanity, which have forced the scientists to find out the new avenues of energy resources. The reserves of oil and gas will be exhausted in 41 and 63 years respectively, if their use remains continue at the present pace. Since the consumption of oil and gas is increasing exponentially, therefore these reserves will be depleted even earlier. Increasing demands in energy and industrialization, as well as environmental concerns caused by the use of fossil fuels, have encouraged researchers to develop alternative fuels and renewable sources of energy [1].

The scientist are already working on the feasibilities and commercialization of solar, wind, and geothermal energies, and recycling of municipal wastes. European countries have planned to use $5.75 \%$ of biofuels by the end of 2010 and $10 \%$ by the year 2020. Biodiesel, derived from renewable biological sources, such as vegetable oils and animal fats, is a popular and environment friendly alternative to fossil fuels because of its renewability, emission, security, and biodegradability [2]. Biodiesel has very similar physical properties just as fossil diesel fuel and even higher cetane number, which allows it to be used directly as substituted fuel in diesel engine without any modification or can be used as blending agent for diesel fuel [3].

Biodiesel can be produced by transesterification with methanol or ethanol using an acid or alkaline catalyst; however, the process of biodiesel/glycerine separation is even more difficult. A factorial design was used to establish the conditions of the transesterification reaction of castor oil, using the central composite design (CCD) and response surface modelling method (RSM) for three-dimensional visualization of the strip reaction conditions with a higher conversion into fatty acid methyl esters. The advantage of castor oil for methyl ester production is that the oil is soluble in alcohol and its transformation therefore does not require heat and consequent energy expenditure as other vegetable oils do for their transformation into biofuel. This characteristic is due to the predominance of ricinoleic acid, which possesses an unsaturated bond. Ricinoleic acid (12-hydroxy-9cis-octadecenoicacid) belongs to the group of hydroxyacids and is characterized by a high molar mass (298.461 $\left.\mathrm{g} \mathrm{mol}^{-1}\right)$ and low melting point $\left(5.5^{\circ} \mathrm{C}\right)$. With the above considerations, in this study methyl ester production from castor oil has been optimized by application of the full-factorial design. The objective of this study was to report experimental data on the production of fatty acid methyl esters from castor oil using $\mathrm{KOH}$ as a catalyst and investigate the factors affecting the yield of biodiesel production from castor

*Corresponding Author: satyamdynamite@gmail.com \& vellurusridevi@yahoo.co.in

Received: 15.03.2019 Accepted: 18.04.2019 Published on: 27.05.2019

Satyanarayana et al., 
oil. A factorial design was used to establish the conditions of the transesterification reaction of castor oil, using the central composite design (CCD). In this present work, FFA analysis using GC and Characterization was also investigated.

\section{MATERIALS AND METHODS}

\subsection{Materials}

Refined castor oil purchased from poorna market, Visakhapatnam, was transesterified using anhydrous methanol and $\mathrm{KOH}$ pellets.

\subsection{Transesterification experiments}

Transesterification reactions were performed in a $250 \mathrm{ml}$ batch reactor equipped with a reflux condenser and a magnetic stirrer, the reaction mixture containing castor oil, methanol and the catalyst $(\mathrm{KOH})$. The oil is first loaded into the reactor, and the temperature adjusted to the desired value. Once the oil reached this value, the alcohol catalyst mixture is added to the reactor and the reaction mixture was continuously stirred at $400 \mathrm{rpm}$. The experiments were carried out and adopted considering the variables, methanol:castor oil molar ratios (4:1- 9:1), temperatures $\left(35-65^{\circ} \mathrm{C}\right)$ and catalyst concentrations $(0.25-1.75 \mathrm{wt} \%)$ of castor oil; and reaction time of (30-120) min.

After an appropriate period of time, excess alcohol was evaporated at a mild temperature under moderate vacuum on a rotary evaporator. The mixture was transferred to a separating funnel, and then allowed to stand for phase separation. After phase separation the remaining mixture was neutralized and subsequently traces of catalyst and alcohol were washed out from the ester mixture with distilled water until the water layer remains completely translucent. The methyl ester was heated at $110^{\circ} \mathrm{C}$ for $30 \mathrm{~min}$ followed by addition of anhydrous calcium chloride to get rid of any water. All experiments were done in triplicate, and the average data are presented.

\subsection{Experimental design}

A factorial design was applied to find out the influence of the operational conditions of the transesterification process, such as methanol: oil ratio, $\mathrm{KOH}$ content, and reaction temperature \& time, on $\%$ yield of ester content. The results were analyzed using the response surface method and analysis of residuals.

\subsection{Gas chromatography analysis}

The methyl ester was analyzed by using gas chromatography. The analysis was carried out by using an Agilent 6890 plus equipped with a HP50+ capillary column $(0.53 \mathrm{~mm}$ - $30 \mathrm{~m}, 0.5 \mathrm{~lm}$ films $)$ and flame ionization detector. Pure nitrogen was used as a carrier gas. The oven temperature program varied from 60 to $260{ }^{\circ} \mathrm{C}$ at a fixed rate of $4^{\circ} \mathrm{C} / \mathrm{min}$. The temperature of the injector and detector was $300{ }^{\circ} \mathrm{C}$. The methyl ester was then subjected to characterization for estimating its fuel properties using ASTM and IP Standard test methods of analysis for petroleum products [4-5].

\section{ACID-ALKALINE TRANSESTERIFICATION 3.1 Effect of Methanol to Oil Molar Ratio}

The reaction was carried out by varying methanol: oil molar ratios from 4:1, 5:1, 6:1, 7:1 8:1 and 9:1, while maintaining the reaction at $60^{\circ} \mathrm{C}, 1 \mathrm{wt} . \%$ catalyst and reaction time $1.5 \mathrm{hr}$ (Figure 1). At a methanol: oil ratio less or equal to $4: 1$, transesterification progressed with FAME yield for the castor oil respectively but a foamy layer was observed during the phase separation, with the lower layer being gelatinous and the upper layer being opaque. This was most probably due to the presence of unreacted triglycerides indicating that the methanol at a 4:1 ratio was insufficient to perform a complete reaction due to the stoichiometric requirement of three mols of alcohol to form one mol of glycerol and three mols of the respective methyl esters. However, the maximum conversion efficiency (yield) was achieved very close to the molar ratio of methanol to oil was 7:1 for COME (88.55\%). With increasing molar ratio to 9:1, then the yield decreases, this is due to accumulation of methanol and viscous nature of the fluid [6].

\subsubsection{Effect of Catalyst (KOH) Weight on Methyl Ester Yield}

The effect of catalyst weight on the transesterification of castor oil was investigated with its concentration varying from 0.25 to 1.75 wt.\% (based on the weight of raw oil), while maintaining methanol to oil molar ratio constant at optimum value. Experimental results from Figure 2 showed that the changes in ester content with catalyst weight followed an asymptotic curve for all the oil samples. As the catalyst weight increased, the conversion of triglyceride, as well as the ester content also increased. Insufficient amount of $\mathrm{KOH}$ resulted in incomplete conversion of triglycerides into the esters as indicated from its lower ester content [7]. For COME, when the amount of catalyst increased from $0.25 \mathrm{wt} . \%$ to 1.5 wt.\% at a constant molar ratio of $6: 1$, conversion to methyl esters increased gradually. The best yields of FAME (84.60 wt \%) for castor oil was reached at a catalyst concentration of $1.5 \mathrm{wt} . \%$ and a further increase in the catalyst concentration did not lead to an increase the conversion but led to extra effort as it was necessary to remove the base catalyst from the product by washing at the end of the reaction. Further increase in the catalyst concentration produces a yield decrease. This behavior is due to the high concentration of an alkaline catalyst which prevail the saponification reaction which form soaps in the presence of fatty acids resulting in emulsion formation between soaps and water molecules [8], which led to the formation of gels possibly owing to an increase in soap content, which increased the viscosity of the FAME formed.

Satyanarayana et al., 
These factors hindered the glycerol separation and hence reduced the apparent ester yield. Thus, $1.5 \mathrm{wt} . \%$ catalyst concentration considered to be the optimum concentration for castor oil samples for further study. These results were qualitatively confirmed as similar trends were observed in other studies conducted by da Silva Nde et al., 2006; Farhat Ali Khan et al., 2011; Umer Rashid et al., 2011[9-11].

Table-1 ANOVA for Response Surface Quadratic Model Analysis of variance table [Partial sum of squares - Type III]

\begin{tabular}{|c|c|c|c|c|c|}
\hline $\begin{array}{c}\text { Source of } \\
\text { variables }\end{array}$ & $\begin{array}{c}\text { Sum of } \\
\text { squares }\end{array}$ & DF & $\begin{array}{c}\text { Mean } \\
\text { square }\end{array}$ & F-value & P-value prob $>$ F \\
\hline Model & 460.12 & 14 & 32.87 & 69.68 & $<0.0001$ significant \\
\hline A-molar ratio & 75.04 & 1 & 75.04 & 159.09 & $<0.0001$ \\
\hline B-catalyst & 0.52 & 1 & 0.52 & 1.09 & 0.3122 \\
\hline C-temp & 5.66 & 1 & 5.66 & 12.01 & 0.0035 \\
\hline D-time & 2.76 & 1 & 2.76 & 5.86 & 0.0286 \\
\hline $\mathrm{AB}$ & 3.60 & 1 & 7.64 & 0.0145 & \\
\hline $\mathrm{AC}$ & 1.47 & 1 & 3.11 & 0.0980 & \\
\hline $\mathrm{AD}$ & 3.80 & 1 & 8.06 & 0.0124 & \\
\hline $\mathrm{BC}$ & 2.63 & 1 & 5.58 & 0.0321 & \\
\hline $\mathrm{BD}$ & 2.88 & 1 & 6.10 & 0.0260 & \\
\hline $\mathrm{CD}$ & 3.30 & 1 & 7.00 & 0.0183 & \\
\hline $\mathrm{A}^{2}$ & 161.11 & 1 & 341.57 & $<0.0001$ & \\
\hline $\mathrm{B}^{2}$ & 135.76 & 1 & 287.84 & $<0.0001$ & \\
\hline $\mathrm{C}^{2}$ & 4.81 & 1 & 10.20 & 0.0060 & \\
\hline $\mathrm{D}^{2}$ & 27.46 & 1 & 58.23 & $<0.0001$ & \\
\hline Residual & 7.07 & 15 & 0.47 & & \\
\hline Lack of Fit & 7.07 & 7 & 1.01 & & \\
\hline Pure Error & 0.000 & 8 & 0.000 & & \\
\hline Cor Total & 467.19 & 29 & & & \\
\hline
\end{tabular}

Table 2 Experimental set up for 2-level-4-factor response surface design and the experimental and predicted values for methyl ester production from Castor oil

\begin{tabular}{|c|c|c|c|c|c|c|}
\hline \multirow{2}{*}{$\begin{array}{c}\text { Run } \\
\text { order }\end{array}$} & $\begin{array}{c}\text { Methanol } \\
\text { to oil } \\
\text { molar } \\
\text { ratio (v/v) }\end{array}$ & $\begin{array}{c}\text { Catalyst } \\
\text { wt. (\%) }\end{array}$ & $\begin{array}{c}\text { Temperature } \\
\text { (0C) }\end{array}$ & $\begin{array}{c}\text { Reaction } \\
\text { time(hr) }\end{array}$ & $\begin{array}{c}\mid c \\
\text { Yield (\%) } \\
\text { values }\end{array}$ & $\begin{array}{c}\text { Predicted } \\
\text { values }\end{array}$ \\
\hline 1 & 7.00 & 1.50 & 50.00 & 1.50 & 89.40 & 88.74 \\
\hline 2 & 7.00 & 1.50 & 60.00 & 1.50 & 80.10 & 80.11 \\
\hline 3 & 8.00 & 2.00 & 55.00 & 1.75 & 81.80 & 82.34 \\
\hline 4 & 7.00 & 1.50 & 60.00 & 1.50 & 89.10 & 88.81 \\
\hline 5 & 6.00 & 2.00 & 65.00 & 1.75 & 77.40 & 77.09 \\
\hline 6 & 8.00 & 2.00 & 55.00 & 1.25 & 80.10 & 80.11 \\
\hline 7 & 7.00 & 2.50 & 60.00 & 1.50 & 84.20 & 84.35 \\
\hline 8 & 8.00 & 1.00 & 55.00 & 1.75 & 83.40 & 82.88 \\
\hline 9 & 7.00 & 1.50 & 60.00 & 1.50 & 85.40 & 84.41 \\
\hline 10 & 9.00 & 1.50 & 60.00 & 1.50 & 90.50 & 90.50 \\
\hline 11 & 7.00 & 1.50 & 70.00 & 1.50 & 80.10 & 80.11 \\
\hline 12 & 7.00 & 1.50 & 60.00 & 2.00 & 90.50 & 90.50 \\
\hline 13 & 7.00 & 1.50 & 60.00 & 1.50 & 79.50 & 80.04 \\
\hline 14 & 7.00 & 0.50 & 60.00 & 1.50 & 90.50 & 90.50 \\
\hline
\end{tabular}

Satyanarayana et al., 


\begin{tabular}{|l|l|l|l|l|l|l|}
\hline 15 & 8.00 & 1.00 & 65.00 & 1.25 & 88.10 & 87.31 \\
\hline 16 & 6.00 & 2.00 & 65.00 & 1.25 & 85.00 & 85.93 \\
\hline 17 & 6.00 & 1.00 & 55.00 & 1.75 & 80.10 & 80.11 \\
\hline 18 & 7.00 & 1.50 & 60.00 & 1.50 & 90.50 & 90.50 \\
\hline 19 & 6.00 & 1.00 & 55.00 & 1.25 & 85.20 & 85.46 \\
\hline 20 & 6.00 & 1.00 & 65.00 & 1.25 & 87.80 & 88.34 \\
\hline 21 & 8.00 & 1.00 & 55.00 & 1.25 & 90.50 & 90.50 \\
\hline 22 & 6.00 & 2.00 & 55.00 & 1.25 & 85.60 & 85.43 \\
\hline 23 & 7.00 & 1.50 & 60.00 & 1.00 & 83.80 & 84.93 \\
\hline 24 & 8.00 & 1.00 & 65.00 & 1.75 & 80.10 & 80.11 \\
\hline 25 & 8.00 & 2.00 & 65.00 & 1.25 & 81.10 & 81.01 \\
\hline 26 & 5.00 & 1.50 & 60.00 & 1.50 & 86.70 & 86.11 \\
\hline 27 & 5.00 & 1.50 & 60.00 & 1.50 & 86.20 & 85.56 \\
\hline 28 & 5.00 & 1.50 & 60.00 & 1.50 & 82.20 & 82.02 \\
\hline 29 & 5.00 & 1.50 & 60.00 & 1.50 & 86.90 & 87.49 \\
\hline 30 & 5.00 & 1.50 & 60.00 & 1.50 & 87.80 & 88.30 \\
\hline
\end{tabular}

\begin{tabular}{|l|l|l|l|}
\hline Std. Dev. & 0.69 & R-Squared & 0.9849 \\
\hline Mean & 84.99 & Adj R-Squared & 0.9707 \\
\hline C.V. $\%$ & 0.81 & Pred R-Squared & 0.8524 \\
\hline PRESS & 68.94 & Adeq Precision & 27.617 \\
\hline
\end{tabular}

Table-3 Composition of methyl esters obtained by of castor oil transesterification using GC-MS

\begin{tabular}{|c|c|c|}
\hline Fatty acid (wt.\%) & Structure & COME \\
\hline Palmitic & C16:0 & 1.01 \\
\hline Stearic & C18:0 & 1.10 \\
\hline Oleic & C18:1 & 3.30 \\
\hline Linoleic & C18:2 & 4.61 \\
\hline Linolenic & C18:3 & 0.48 \\
\hline Arachicdic & C20:0 & - \\
\hline Paullicnic & C20:1 & - \\
\hline Behenic & C22:0 & - \\
\hline Erucic & C22:1 & - \\
\hline Lignoceric & C24:0 & - \\
\hline Eicosenoic acid & C20:2 & 0.29 \\
\hline Ricinoleic acid & C18:1-0H & $\mathbf{8 9 . 1 5}$ \\
\hline $\boldsymbol{\Sigma S A T}$ & & 2.11 \\
\hline $\boldsymbol{\Sigma M U F \boldsymbol { A }}$ & & $\mathbf{9 2 . 7 4}$ \\
\hline $\boldsymbol{\Sigma P U F \boldsymbol { A }}$ & & 5.09 \\
\hline
\end{tabular}


Table- 4 Physiochemical properties of test fuel in comparison to ASTM methyl ester standards

\begin{tabular}{|c|c|c|c|c|}
\hline Property & Units & $\begin{array}{c}\text { Diesel } \\
\text { (HC) }\end{array}$ & COME & $\begin{array}{c}\text { Methyl ester } \\
\text { ASTM } \\
\text { (D6751-02) }\end{array}$ \\
\hline CarbonChain & $\mathrm{Cn}$ & C8-C16 & $\begin{array}{c}\text { FAME } \\
\text { C16-C20 }\end{array}$ & $\mathrm{C} 12-\mathrm{C} 22$ \\
\hline $\begin{array}{c}\text { Lowercalorific } \\
\text { value }\end{array}$ & $\mathrm{kJ} / \mathrm{kg}$ & 42500 & 37120 & 37518 \\
\hline Density & $\mathrm{kg} / \mathrm{m}^{3}$ & 820 & 946 & $870-900$ \\
\hline $\begin{array}{c}\text { Kinematicviscosity } \\
@ 40^{\circ} \text { CD } 445\end{array}$ & $\mathrm{~mm}^{2} / \mathrm{s}$ & 2.25 & 15.17 & $1.9-6.0$ \\
\hline $\begin{array}{c}\text { CetaneNumber } \\
\text { D613 }\end{array}$ & -- & 48 & 48.9 & $47 \mathrm{~min}$. \\
\hline $\begin{array}{c}\text { Flashpoint, } \\
\text { Closedcup D93 }\end{array}$ & ${ }^{\circ} \mathrm{C}$ & 66 & 185 & $130 \mathrm{~min}$ \\
\hline Fire point & ${ }^{\circ} \mathrm{C}$ & & 203 & --- \\
\hline Acid value & & & 0.752 & --- \\
\hline Iodine value & $\begin{array}{c}\mathrm{g} \\
\text { Iodine } / 100 \mathrm{~g}\end{array}$ & 38 & 82 & $120 \max$ \\
\hline Pour point & ${ }^{\circ} \mathrm{C}$ & -6 & -30 & -15 to 10 \\
\hline Cloud point & ${ }^{\circ} \mathrm{C}$ & & -18 & --- \\
\hline
\end{tabular}

\subsubsection{Effect of Reaction temperature}

In order to study the effect of reaction temperature on FAME formation, the experiments were conducted at temperature ranging from 35 to 65 ${ }^{\circ} \mathrm{C}$ at ${ }^{5} \mathrm{O} \mathrm{C}$ intervals. The effect of reaction temperature was shown in Figure 3. Experimental results showed that the transesterification reaction could proceed within the temperature range studied but the reaction time to complete the reaction varied significantly with reaction temperature. The maximum conversion efficiency during transesterification for COME $(85.72 \%)$ was obtained at $60^{\circ} \mathrm{C}$. With the temperature increased above optimum, the product yield started to decrease with respect to all the oil samples used in the study, the reason for this is that higher temperature accelerates the side saponification reaction of triglycerides and although a reflux condenser was used in the experimental set up to avoid methanol losses when the reaction temperature approaches or exceeds the boiling point of methanol $\left(65^{\circ} \mathrm{C}\right)$, the methanol molecules would vaporize and form a large number of bubbles that then inhibits the reaction. da Silva Nde et al., 2006 [9] reported a similar yield for COME at a slightly higher temperature of $65^{\circ} \mathrm{C}$ although the work was done with a higher methanol: oil ratio of 9:1.

\subsubsection{Effect of Reaction Time}

Figure 4 shows the methyl ester yield for the transesterification of castor oil in different reaction time from $0.5 \mathrm{hr}$ to $2 \mathrm{hr}$. In the initial stages of the transesterification reaction, production of methyl ester was rapid until the reaction has reached equilibrium. As it can be observed, the ester content increased with reaction time at the beginning, reached a maximum yields at a reaction time of $1.5 \mathrm{hr}$ for COME (90.50\%) and then gradually decrease with increasing further the reaction time. Beyond the optimal point, the reaction starts to reverse in backward direction towards reactants. This phenomenon occurred due to the reversibility of transesterification reaction $[12,13]$. $\mathrm{KOH}$ catalyst has a tendency to adsorb products when reactant was lack [14].Therefore too long reaction time also reduces the methyl ester yield as the $\mathrm{KOH}$ catalyst can absorb the product. A higher FAME yield of 90.50 $\%$ was recorded for COME at $1.5 \mathrm{hr}$. The COME used had the highest amount of short carbon chains of fatty acids. These short carbon chains of fatty acids have less steric hindrance in comparison to long carbon chains of fatty acids, therefore have more possibility of contact with catalyst consequently contributing to the reduced conversion time and corresponding increased methyl ester yield [15].

3.2 Optimization of process parameters using a factorial design and a surface response designCOME Evaluation of regression model for transesterification efficiency

The correlation between the experimental process variables and the transesterification efficiency was evaluated using the CCD modelling technique. Second order polynomial regression equation was fitted between the response (Transesterification efficiency,

Satyanarayana et al., 
(Y)) and the process variables: methanol to oil molar ratio $A$, catalyst weight $B$, reaction temperature $C$ and Time D. From Table 1, the ANOVA results showed that the quadratic model is suitable to analyse the experimental data. The model in terms of the coded values of the process parameters is given by Eq. 5.1.

$\mathrm{Y}=84.85+11.89 \mathrm{~A}+1.08 \mathrm{~B}+8.48 \mathrm{C}-2.50 \mathrm{D}+2.35 \mathrm{AB}-$ $3.00 A C+2.38 A D+3.67 B C-2.10 B D+4.50 C D-8.24 A^{2}-$ $9.18 B^{2}-6.91 C^{2}-4.13 D^{2}-------E q .(5.1)$

To develop a statistically significant regression model, the significance of the regression coefficients was evaluated based on the p-values. The coefficient terms with $\mathrm{p}$-values more than 0.05 were insignificant and were removed from the regression model. $\mathrm{p}$ values $<0.05$ indicate that the model terms are significant. Final Equation in terms of actual factors is given by Eq. 5.2.

$\mathrm{Y}=-92.63+29.08 \mathrm{~A}+17.94 \mathrm{~B}+1.62 \mathrm{C}+14.03 \mathrm{D}+$ $1.174 \mathrm{AB}-0.075 \mathrm{AC}+2.38 \mathrm{AD}+0.198 \mathrm{BC}-4.200 \mathrm{BD}+$ $0.449 C D-2.06 A^{2}-9.17 B^{2}-0.017 C^{2}-16.51 D^{2}$

The analysis of variance indicated that the quadratic polynomial model was significant and adequate to represent the actual relationship between transesterification efficiency and the significant model variables as depicted by very small $p$-value $(<0.0001)$. The significance and adequacy of the established model were further elaborated by a high value of coefficient of determination $\left(\mathrm{R}^{2}\right)$ value of 0.9849 and adj. $\mathrm{R}^{2}$ value of 0.9707 (Table-2). This means that the model explains $98.49 \%$ of the variation in the experimental data. The adequate correlation between the experimental values of the independent variable and predicted values further showed the adequacy of the model and low value of coefficient of variation (C.V) $(0.81 \%)$, are an indication of precision of fitted model.

The Model F-value of 69.68 implies the model is significant. There is only a $0.01 \%$ chance that a "Model F-Value" this large could occur due to noise. Values of "Prob > F" less than 0.0500 indicate model terms are significant. In this case $A, C, D, A B, A D, B C, B D, C D, A^{2}$, $\mathrm{B}^{2}, \mathrm{C}^{2}, \mathrm{D}^{2}$ are significant model terms. Values greater than 0.1000 indicate the model terms are not significant. If there are many insignificant model terms (not counting those required to support hierarchy), model reduction may improve your model.

The "Pred R-Squared" of 0.8524 is in reasonable agreement with the "Adj R-Squared" of 0.9707. "Adeq Precision" measures the signal to noise ratio. A ratio greater than 4 is desirable. Your ratio of 27.617 indicates an adequate signal. This model can be used to navigate the designspace. Proceed to Diagnostic Plots, Normal probability plot of the studentized residuals to check for normality of residuals (Figure 5). The coefficient of determination $\left(\mathrm{R}^{2}\right)$ obtained by this model was 0.9849 , indicating that $92.72 \%$ of the variable in methyl ester yield can be explained by the fitted model,i.e the regression is signifivcant as illustrated in Figure 6 [16].

\subsubsection{Response surface estimation}

The interactive effects of the process variables on the transesterification efficiency were studied by plotting three dimensional surface curves against any two independent variables, while keeping other variables at their central $(0)$ level. The 3D curves of the response (transesterification efficiency) from the interactions between the variables are shown in Figures 7-12. The response surface curves were plotted to understand the interaction of the variables and to determine the optimum level of each variable for maximum response. The elliptical shape of the curves indicates a good interaction of the two variables and circular shape indicates no interaction between the variables. The curves obtained in this study showed that there is a relative significant interaction between all the variables. Optimum conditions were also obtained from the response surface plots. The stationary point or central point is the point at which the slope of the contour is zero in all directions. The coordinates of the central point within the highest contour levels in each of the plots will correspond to the optimum values of the respective variables. The maximum predicted yield is indicated by the surface confined in the smallest curve of the contour diagram. The optimal conditions for Castor oil ME as follows: methanol to oil molar ratio $7: 1$, temperature $60^{\circ} \mathrm{C}$, time $1.5 \mathrm{hr}$, catalyst $1.5 \mathrm{wt} \%$. This optimized condition was validated with the actual methyl ester yield in $90.50 \%$. To confirm this optimum values, experiments were performed at these values and the experimental response value was $90.50 \%$.

This showed that the model correctly explains the influence of the process variables on the production of FAME from Castor ME. The predicted values versus actual values for the methyl ester yield with adjusted$\mathrm{R}^{2}$ value of 0.9707 shows the model with $97.07 \%$ of variability. The predicted value and the experimental values were in reasonable agreement $\left(\mathrm{R}^{2}\right.$ close to unity), which means that the data fit well with the model and give a convincingly good estimate of response for the system in the range studied. In addition, investigation on residuals to validate the adequacy of the model was performed. Residual is the difference between the observed response and predicted response. This analysis was examined using the normal probability plot of residuals. The normal probability plot of the residuals shows that the errors are distributed normally in a straight line and insignificant. Similar results were also reported in the literature by Lee et al., 2011[17].

\section{Satyanarayana et al.,}




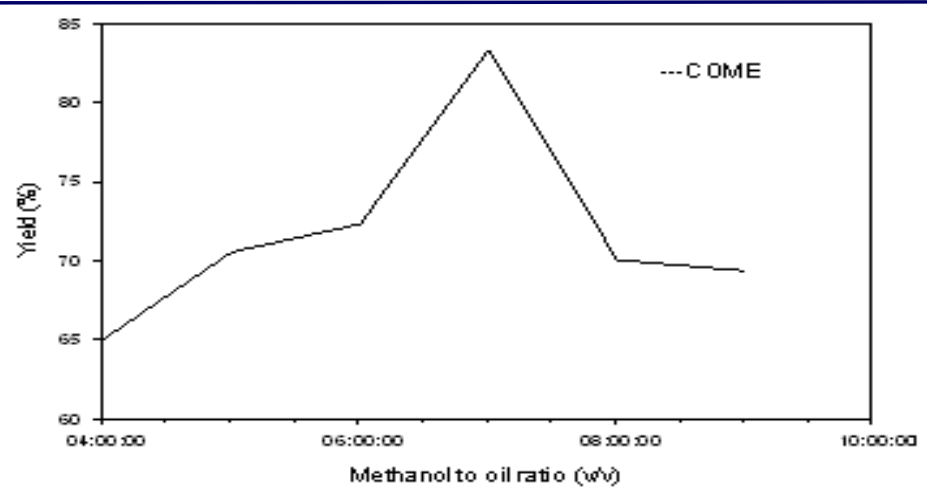

Figure-1 Effect of Methanol to oil Molar Ratio on methyl ester yield

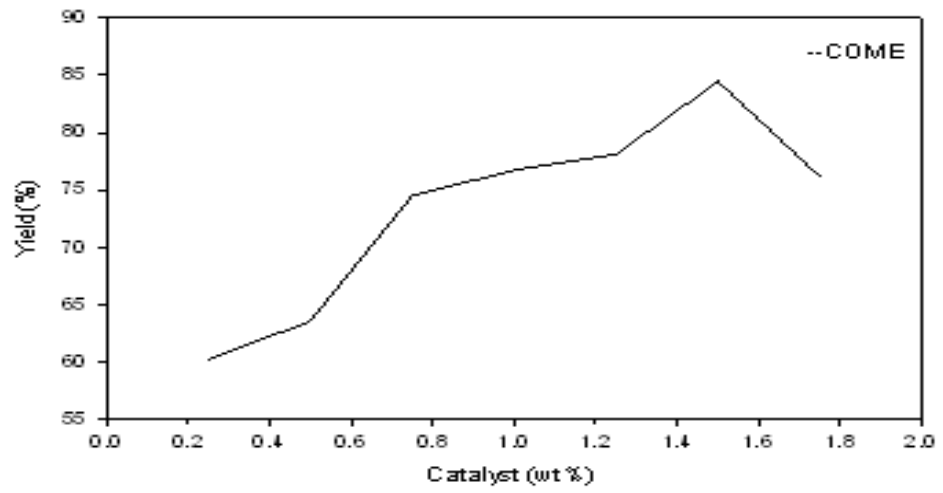

Figure-2 Effect of Catalyst (KOH) Weight on Methyl Ester Yield

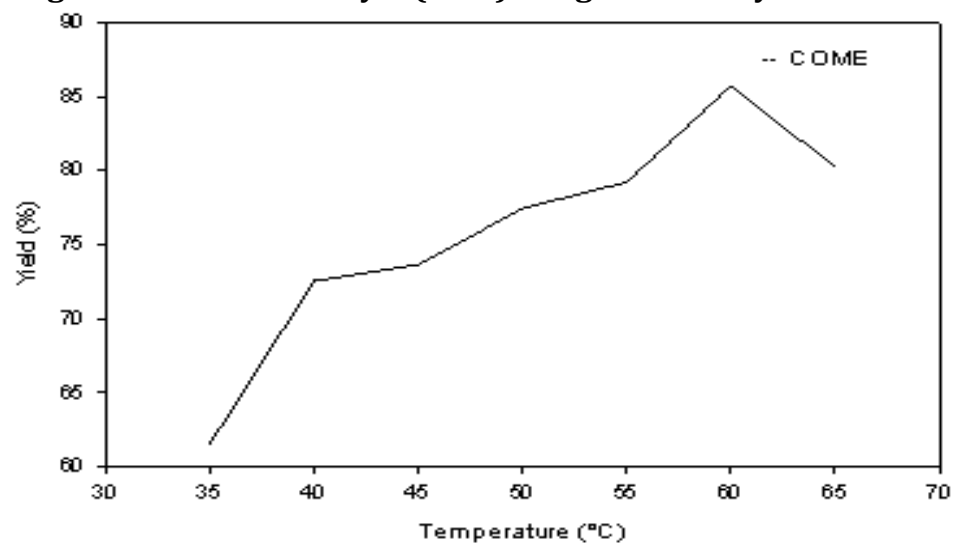

Figure-3 Effect of Reaction temperature on Methyl Ester Yield

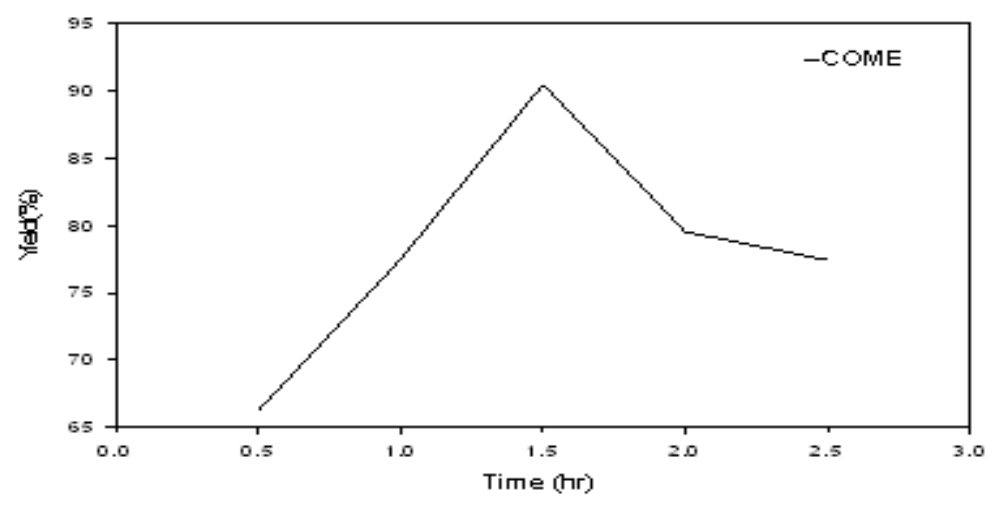

Figure-4 Effect of Reaction time on Methyl ester Yield

Satyanarayana et al., 


\subsection{FFA (Free fatty acid) Analysis}

\subsubsection{Methyl ester composition}

The fatty acid profiles are the major indicators of the properties of any diesel. In this work, methyl ester (methyl ester) from castor oil had a fatty acid composition as depicted in Table 3 The composition of fatty acid affects various properties of methyl ester, such as oxidation stability, low temperature flow properties and lubricity. Castor oil contains a number of fatty acids similar to those in cooking oils such as oleic, palmitic acids etc. However, among vegetable oils castor oil is distinguished by its high content of ricinoleic acid (about 89.15\%), castor oil unsaturated bond, molecular weight $(298)$, low melting point $\left(5^{\circ} \mathrm{C}\right)$ makes it industrially useful. Castor oil is unique among all fats and oils, it has an unusual composition of a triglyceride of fatty acids, and it is the only source of an 18-carbon hydroxylated fatty acid with one double bond. Methyl ester derived from castor oil rates high among other oils with ash content of about $0.02 \%$, sulfur content less than $0.04 \%$, negligible potassium content, $35 \mathrm{GJ} / \mathrm{T}$ which compares favorably with other vegetable oils and petro diesel of about $45 \mathrm{GJ} / \mathrm{T}$, and viscosity that is much higher than petro diesel, but this major bottleneck of the viscosity can be considerably reduced by transesterification produces a very efficient source of methyl ester. The castor plant is used as a lubricant for high-performance engines.

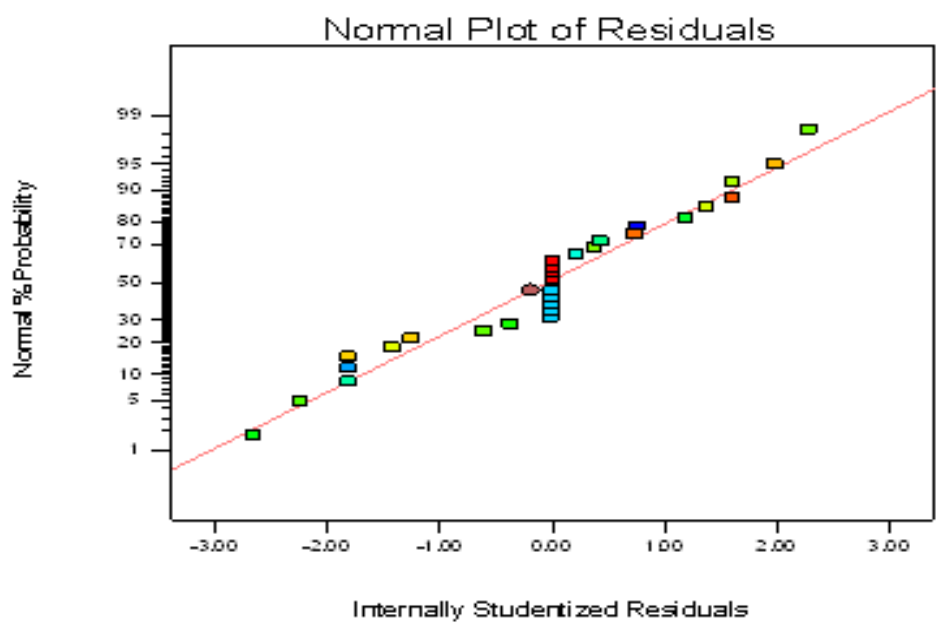

Figure 5 Normal probability plot of the residual

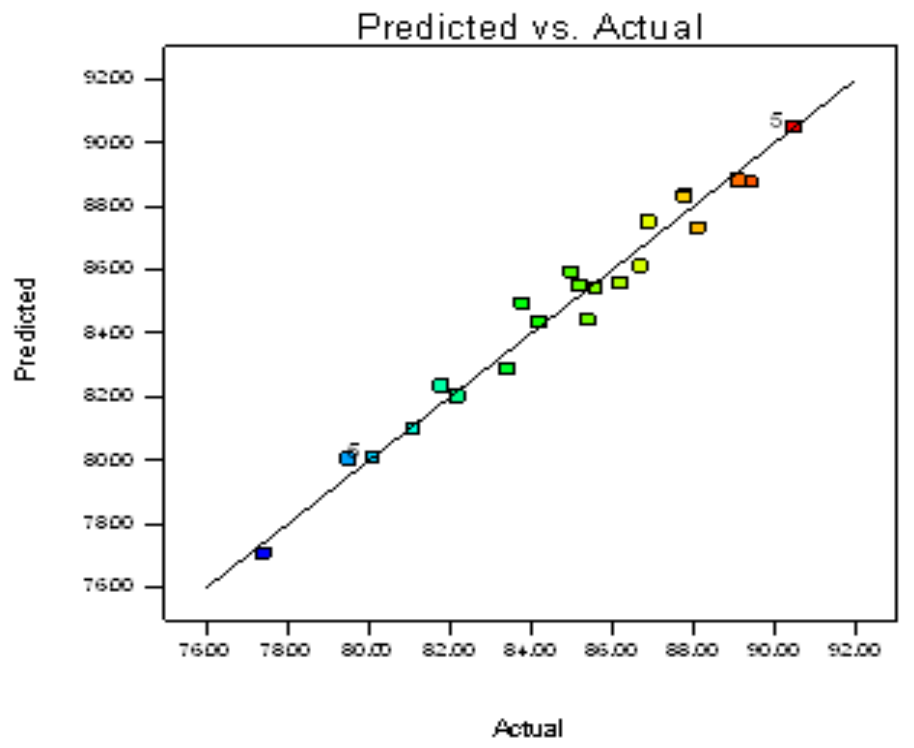

Figure 6 Predicted versus actual FAME yield

Satyanarayana et al., 


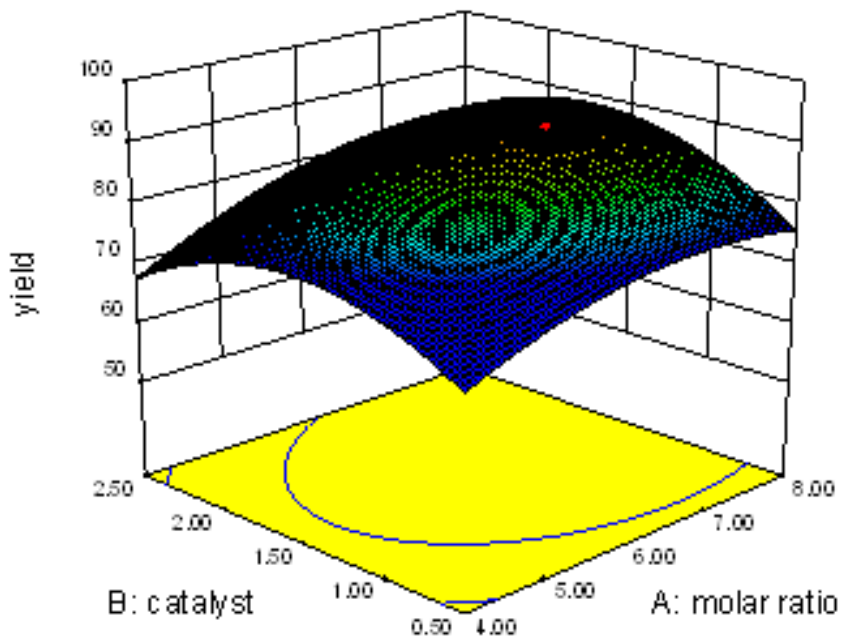

Figures 7-Surface plot between methanol to oil molar ratio and catalyst weight against methyl ester yield

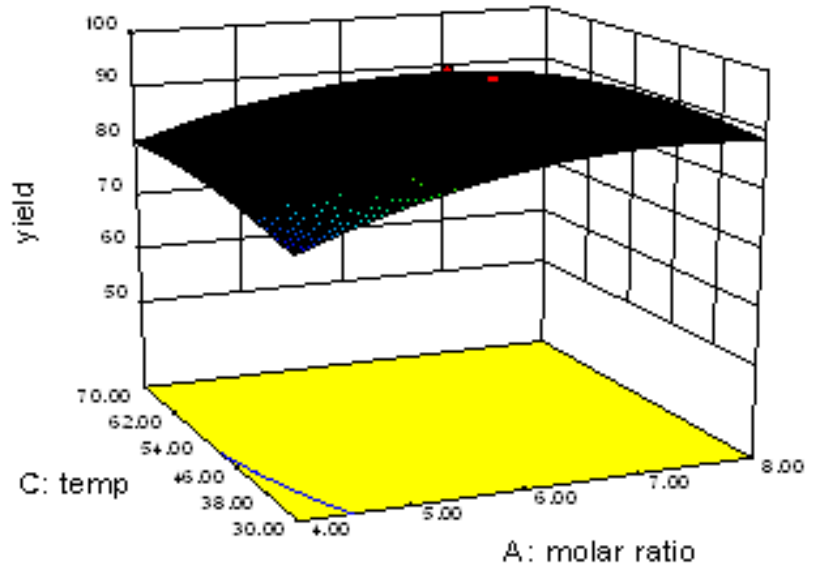

Figures 8 Surface plot between methanol to oil molar ratio and temperature against methyl ester yield

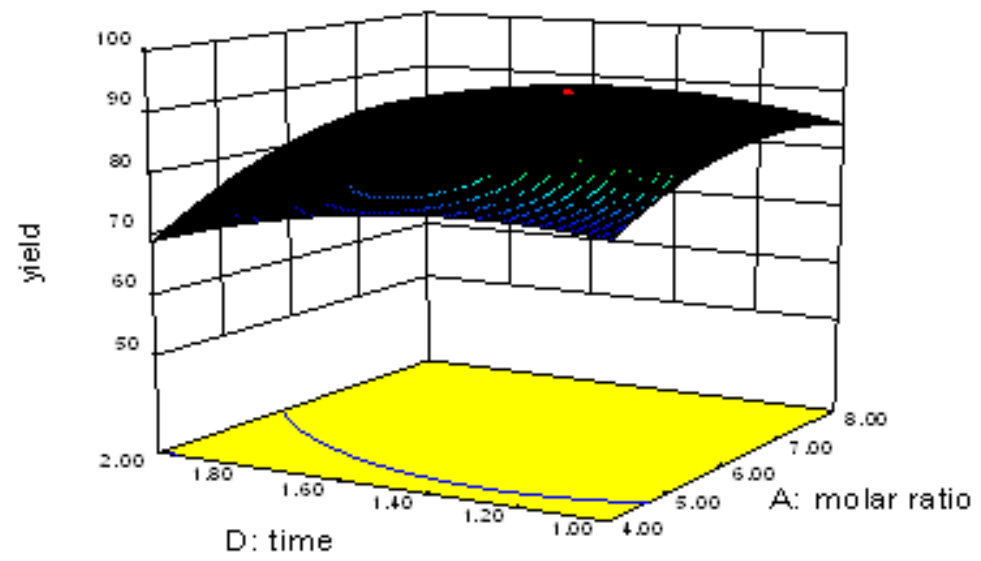

Figures 9 Surface plot between methanol to oil molar ratio and time against methyl ester yield 


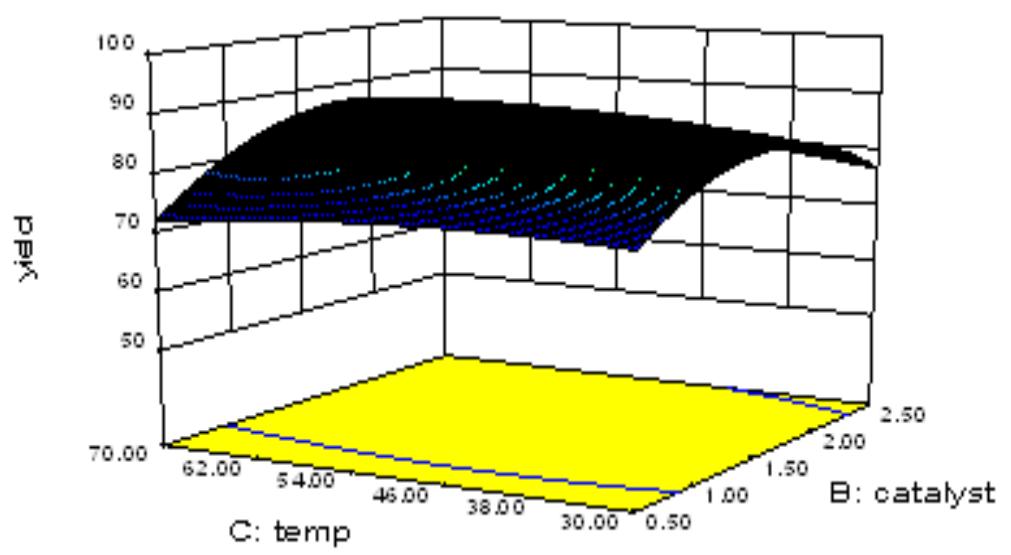

Figures 10 Surface plot between catalyst weight and temperature against methyl ester yield

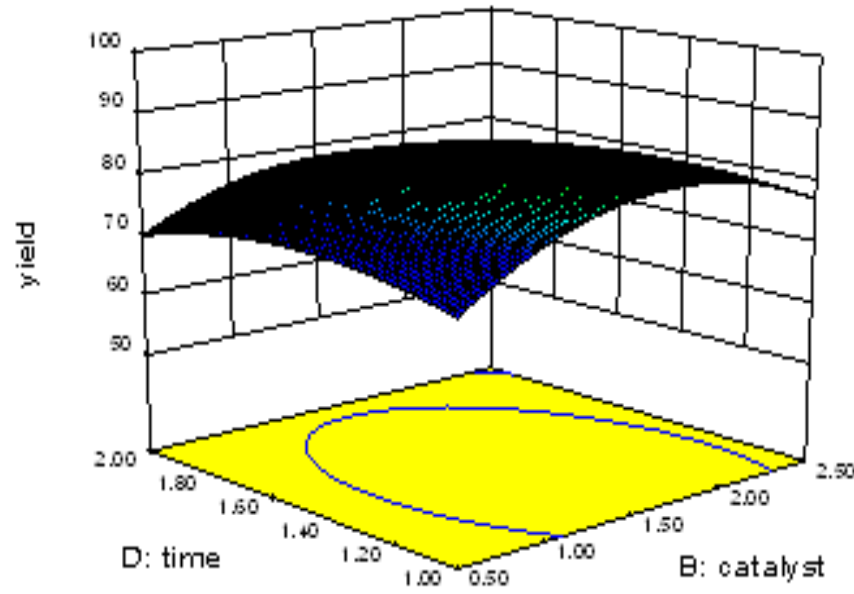

Figures 11 Surface plot between catalyst weight and time against methyl ester yield

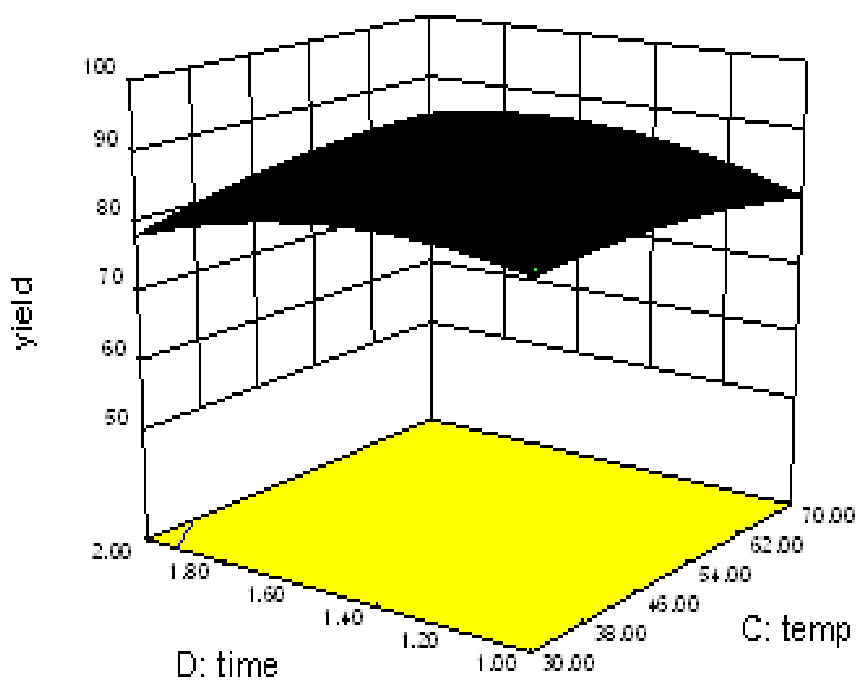

Figures 12 Surface plot between temperature and time against methyl ester yield

Satyanarayana et al., 


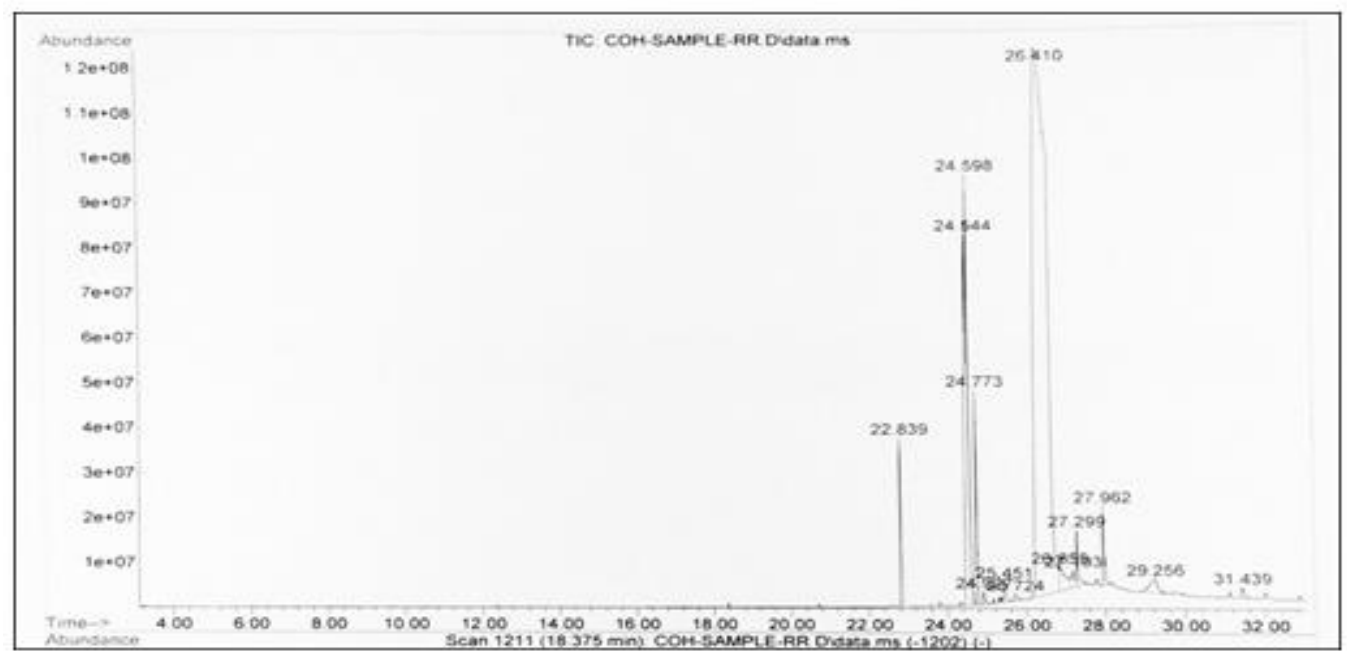

Figure 13: GC-MS peaks of Castor oil FAME

\subsubsection{GC- MS Analysis of COME}

From the Figure 13, the fatty acid analysis of the castor methyl ester obtained from GCMS analysis gives the details of the fatty acids present in the sample obtained at the retention times like 22.839, 24.598, 24.773 etc. which are tabulated in Table 3.

\subsection{Physiochemical properties of Castor oil}

Castor oil that was utilized as a feedstock in the production of methyl ester was characterized to determine their physiochemical properties such as density, $\mathrm{pH}$, viscosity, acid value, iodine value etc. The results obtained on the properties of oils were compared with that of ASTM methyl ester standards and the results obtained are presented in Table-4.The high demand to replace petroleum fuel makes renewable and sustainable sources such as Castor oil a main focus feedstock for methyl ester production.

\section{CONCLUSIONS}

Castor oil was transesterified with $\mathrm{KOH}$ as catalyst and methanol to form methyl ester production. For the COME, the best set of parameters are-methanol to oil molar ratio - 7:1, catalyst concentration- 1.5 wt.\%, reaction temperature- $60^{\circ} \mathrm{C}$ and reaction time- $1.5 \mathrm{hr}$ resulting yield of $90.50 \%$. In this work a study on the optimization of COME transesterification reaction parameters were also carried out by RSM. The statistical models developed from COME for predicting yield showed a good agreement between the experimental and calculated values. The GC-MS of COME reported more MUFA and less SFA. From the FTIR analysis it is clear that both types of FAME contain same kind of bonds and functional groups at different concentrations. The COME has higher $\mathrm{C}-\mathrm{O}$ bonds. Physico-chemical properties of methyl esters are influenced by the structural features of fatty acids and characterized by its properties of the methyl ester according to the ISO norms and are compared to that of petroleum diesel and the viscosity of COME is nearer to that of diesel and the calorific value is less than that of diesel, more lubricating than diesel, so it increases the life of engines.

\section{REFERENCES}

[1]. Ramaraj, R., Dussadee, N., Whangchai, N., Unpaprom, Y., 2015. Microalgae Biomass as an Alternative Substrate in Biogas Production. International Journal of Sustainable and Green Energy, 4, 1-1, 13-19.

[2]. Unpaprom, Y., Tipnee, S., Ramaraj, R., 2015. Biodiesel from Green Alga Scenedesmus acuminatus. International Journal of Sustainable and Green Energy, 4, 1-1, 1-6.

[3]. Bello, E.I., and Makanju, A., 2011. Production, characterization and evaluation of castor oil biodiesel as alternative fuel for diesel engines. Emerging Trends in Engineering and Applied Science, 2: 525-530.

[4]. Gad, M.S., Araby El, R., Abed, K.A., El-Ibiari, N.N., El Morsi, A.K., El-Diwani, G.I., 2017. Performance and emissions characteristics of C.I. engine fueled with palm oil/palm oil methyl ester blended with diesel fuel. Egypt. J. Petroleum, 27 (2), 215-219.

[5]. Narwal, S.K., Saun, N.K., Dorga, P., Chauhan, G., Gupta, R., 2015. Production and characterization of bio diesel using non-edible castor oil by immobilized lipase from Bacillus aerius. Annual report, Biomed.Res.Int., ID 281934, 1-6.

[6]. Meher, L.C., Dharmagadda, V.S.S., Naik, S.N., 2006a. Optimization of alkaline catalyzed transesterification of pongamiapinnata oil for production of methyl ester. Bioresour. Technol, 97, 1392-1397.

Satyanarayana et al., 
[7]. Thanh, L. T., Okitsu, K., Sadanaga, Y., Takenaka, N., Maeda, Y., Bandow, H., 2010. Ultrasound assisted production of methyl ester fuel from vegetable oils in a small scale circulation process. Bioresource Technology, 101, 639-645.

[8]. Georgogianni, K.G., Kontominas, M.G., Pomonis, P.J., Avlonitis, D., Gergis, V., 2008. Conventional and in situ transesterification of sunflower seed oil for the production of methyl ester. Fuel Process. Technol, 89, 503-509.

[9]. da Silva Nde, L., Maciel, M.R., Batistella, C.B., MacielFilho, R., 2006. Optimization of methyl ester production from castor oil. Appl Biochem Biotechnol, 129-132, 405-14.

[10]. Farhat Ali Khan., Javid Hussain., Mohammad Zahoor., Syed Muhammad Mukarram Shah., Asfandyar Khan., NaseemUllah., MuneeburRehman., Muhammad Khuram., 2011. Methyl ester Production from Mustard Oil, Coal Ash Using as Catalyst. Middle-East Journal of Scientific Research, 8 (5), 866-872.

[11]. UmerRashid., HafizAbdulRehman., IrshadHussain., MuhammadIbrahim., Muhammad., SajjadHaider., 2011. Muskmelon (Cucumismelo) seed oil: A potential non-food oil source for methyl ester production. Energy, 36 (9), 5632-5639.

[12]. Samart, C., Sreetongkittikul, P., Sookman, C., 2009. Heterogeneous catalysis of transesterification of soybean oil using KI/ mesoporous silica. Fuel Processing Technology, 90 (7-8), 922-925.

[13]. Santana, A., Mac,aira, J., Larrayoz, M. A., 2012.Continuous production of methyl ester using supercritical fluids: a comparative study between methanol and ethanol. Fuel Processing Technology, 102, 110-115.

[14]. Taufiq-Yap, Y. H., Lee, H. V., Hussein, M. Z., Yunus, R., 2011. Calcium-based mixed oxide catalysts for methanolysis of Jatrophacurcasoil to methyl ester. Biomass and Bioenergy, 35(2), 827-834.

[15]. Lucena, I.L., Silva, G.F., Fernandes, F.A.N., 2008. Methyl ester Production by Esterification of Oleic Acid with Methanol Using a Water Adsorption Apparatus. Ind. Eng. Chem. Res, 47,6885 - 6889 .

[16]. Kiany, S.B., Cavalcante., Maria, N.C., Penha., Karlene, K.M., Mendonça., Hilton, C., Louzeiro., Antonio, C.S., Vasconcelos., Adeilton, P., Maciel., Antonio, G., de Souza., Fernando, C., Silva., 2010. Optimization of transesterification of castor oil with ethanol using a central composite rotatable design (CCRD). Fuel, 89, 1172-1176.

[17]. Lee, H.V., Yunus, R., Juan, J.C., Taufiq-Yap, Y.H., 2011. Process optimization design for Jatrophabased methyl ester production using response surface methodology. Fuel Process Technology, $92,2420-2428$.

All @ 2019 are reserved by International Journal of Advanced Science and Engineering. This Journal is licensed under a Creative Commons Attribution-Non Commercial-ShareAlike 3.0 Unported License.

Satyanarayana et al., 